\title{
UMA ABORDAGEM HUSSERLIANA AO PROBLEMA DA REFERÊNCIA
}

André Barata

Universidade da Beira Interior/IFP*

I

(Descritivismo e Teoria causal da referência)

A teoria descritivista afirma que as extensões dos termos referenciais são determinadas exclusivamente pelas suas intensões. Por outras palavras, a intensão de um termo referencial é condição suficiente para a determinação da sua extensão. E diz-se descritivista porque, por um lado, assenta na determinação da intensão desse termo e porque, por outro lado, esta determinação se faz, empregando o vocabulário de Russell, através de uma descrição definida. No caso de termos genuinamente referenciais (como nomes próprios ou termos para tipos naturais), considera-se que a fixação da referência se faz via uma descrição definida associada ao termo.'

Universidade da Beira Interior/Instituto de Filosofia Prática.

1 Cf. Russell, 1905. Reportaremos o descritivismo a duas teses de Russell - por um lado, a sua teoria das descrições definidas, segundo a qual estas não são termos genuinamente referenciais; por outro, a sua teoria de que os nomes próprios são abreviaturas de descrições definidas. Note-se, porém, que o descritivismo russelliano não apaga o facto de Russell estabelecer uma clara distinção entre duas funções semânticas distintas. Para este ponto, cf. Adriana Graça, 2002. "Russell, de forma sugestiva [...] defende em 'On Denoting' e no seu trabalho filosófico subsequente que a nomes próprios genuínos e a termos descritivos estão na verdade associadas duas funções semânticas distintas, a de referir e a de denotar, respectivamente. Esta tese é na verdade resultante da sua descoberta segundo a qual a relação semântica que existe entre um nome e objecto do qual é representante é de natureza essencialmente diferente da relação semântica que existe entre um termos descritivo e o objecto que ele identifica (inesmo no caso em que este objecto existe e é único). No primeiro caso temos uma relação directa e imediata, no segundo uma relação indirecta e mediada, na qual um certo objecto é identificado por meio da satisfação de certos predicados." Adriana Graça, 2002: 6-7. No que 
Esta posição teórica obriga a duas pressuposições problemáticas no que respeita aos termos genuinamente referenciais. A primeira pressuposição resume-se à tese descritivista de que os termos genuinamente referenciais refeririam o que uma presumível descrição definida associada refere. O problemático aqui prende-se com o facto de, em situações contrafactuais, como ilustrou Saul Kripke, os nomes próprios (designadores rígidos) e as descrições definidas (designadores flexíveis) terem comportamentos semânticos diferentes, a saber, enquanto aqueles obtêm necessariamente os mesmos referentes, estas só contingentemente obtêm os mesmos referentes. Por exemplo, numa situação contrafactual, Aristóteles poderia muito bem não ter sido o maior filósofo da Antiguidade; significa isto que a descrição definida 'O maior filósofo da Antiguidade' obteria um referente diferente na situação contrafactual sem que o nome próprio 'Aristóteles' deixe, apesar disso, de referir Aristóteles. Ora, não se podendo deixar de considerar esta diferença de comportamento entre nomes próprios e descrições definidas, então não será aceitável afirmar que a referência de um nome próprio (ou de qualquer outro termo genuinamente referencial) seja suportada por uma descrição definida, i.e, seja o resultado de uma determinação intensional. ${ }^{2}$

A segunda pressuposição problemática prende-se com a ideia de que o uso competente de um termo genuinamente referencial obrigaria à posse, por parte do sujeito que emprega o termo, de uma descrição definida associada a esse termo. Significa isto que o utente de um termo genuinamente referencial (seja um nome próprio, um termo para espécie natural ou um qualquer termo geral) não poderia deixar de estar na posse do conhecimento do conjunto de propriedades inclusas na descrição definida associada ao termo. Ora, tal vínculo colide com a existência de usos igualmente competentes de termos genuinamente referenciais por parte de sujeitos linguísticos que, não obstante, revelam variados graus de conhecimento (ou de ignorância) de descrições associáveis a esses termos.

respeita ao Descritivismo, pode-se ler ainda: “A tese segundo a qual os nomes próprios da linguagem corrente são descrições definidas disfarçadas [...] corresponde na literatura filosófica àquilo que é conhecido por Teoria Descritivista dos Nomes. Efectivamente, para quem aceita que nomes são descrições disfarçadas, é a Teoria das Descrições Definidas que está na base da explicação de como é que nomes têm sentido (genericamente falando): eles têm sentido porque ao seu uso está associado um Sinn fregeano, um modo de apresentação do objecto, o qual consiste na verdade na descrição definida por meio da qual é possível identificar quer o conteúdo conceptual do nome quer o objecto que é a sua referência." (Adriana Graça, 2002: 10-11) designators. Certainly they seem to satisfy the intuitive test mentioned above: although someone other than the U.S. President in 1970 might have been the U.S. President in 1970..., no one other than Nixon might have been Nixon." (Kripke, 1980: 281-282). Cf. também Lycan, 2000: 43-44. 
Concluindo, parece certo que estas duas pressuposições - até cada uma por si - dão razoavelmente conta do carácter insatisfatório do descritivismo enquanto teoria sobre a determinação da referência de termos genuinamente referenciais (como nomes próprios ou outros designadores rígidos), razão mais que suficiente para que se procure encontrar uma teoria alternativa.

A teoria causal da referência afirma que o uso actual de um termo genuinamente referencial (seja um nome próprio seja um termo para espécie natural) resulta necessariamente dos usos precedentes, numa série causal regressiva que tem o seu início no primeiro contacto com o objecto por ele designado. ${ }^{3}$

Esta teoria expõe assim uma explicação da referência em dois passos: há um momento inaugural em que é convencionada a relação de referência entre um certo termo e um certo objecto; e, depois, há usos desse termo que decorrem causalmente da primeira atribuição.

Esta breve exposição faz ressaltar um dos aspectos mais salientes na contraposição entre as duas teorias, a saber - o descritivismo, em geral, visa determinar a referência de um nome através do conhecimento associado a esse nome, conhecimento que deveria, em consequência, estar na posse de cada falante que faz um uso competente do nome; a Teoria causal desvincula a capacidade de uso competente de um nome de uma exigência de posse do conhecimento associado.

Nesta contraposição é fácil identificar duas importantes vantagens da Teoria causal face ao descritivismo. Em primeiro lugar, liberta a fixação da referência de uma sua necessária determinação atributiva, tal como pressupunha o descritivismo. Mais em particular, e no que respeita aos termos genuinamente referenciais, a Teoria causal apresenta uma explicação da fixação da referência sem a pressuposição de uma descrição definida associada. Por isso, esta teoria não é afectada pela diferença de comportamento entre termos genuinamente referenciais e termos denotativos quando os empregamos em situações contrafactuais.

Em segundo lugar, a TCR consegue justificar, como nunca o conseguiu o descritivismo, a evidente diversidade de graus de conhecimento (ou de ignorância) a respeito de objectos por parte de falantes que, ainda assim, os referem através de um uso competente de nomes. Por exemplo, embora a generalidade dos falantes de Português não conheça o número atómico do ouro, não deixa por isso de se referir adequadamente a esse metal, i.e, através do uso correcto da expressão linguística 'ouro'.

4 Gareth Evans expõe esta vantagem da Teoria causal da referência nos seguintes termos "The description theory of what a name denotes holds that, associated with each name as used by a group of speakers who believe and intend that they are using the name with the same denotation, is a description or a set of descriptions cullable from their beliefs which an item has to satisfy to be the bearer of the name... The theory is by no means committed to the 


\section{II \\ (Expressão e Significação)}

Na primeira das suas Investigações Lógicas $(L U)$, intitulada 'Expressão e Significação', Husserl explicita a distinção entre dois planos de abordagem um pelo qual se tematiza a expressão (Ausdruck) enquanto acontecimento da vida psíquica de uma consciência, outro em que se tematiza a mesma expressão, mas apenas na sua objectiva significação, i.e, exactamente no que nela é expresso. Logo no §11 da referida Investigação, atesta-se esta importante distinção:

"Até agora temos considerado a expressão plena de sentido como uma vivência concreta. Em vez dos dois factores: o fenómeno da expressão e as vivências de dar sentido (e respectivamente de preencher o sentido), vamos considerar agora o que de certo modo está dado "em" eles: a expressão, o seu sentido e a objectividade correspondente. Fazemos, pois, uma viragem que, afastando-se da relação real entre os actos, se vira para a relação ideal dos seus objectos (e respectivamente de seus conteúdos). A consciência subjectiva cede o lugar à objectiva". 5

Esta dupla face, digamos, entre uma materialidade do acto expressivo aquilo por que chega realmente a haver acto - e uma sua idealidade - aquilo por que chega esse acto a ser expressivo -, não pode deixar de ser assinalada a partir do momento em que se reconhece que a diferentes enunciados linguísticos pode corresponder a mesma expressão, ou seja, que diferentes afirmações podem afirmar o mesmo. Por exemplo, seja a frase 'A soma dos ângulos internos de um triângulo é igual à de dois ângulos rectos'. Naturalmente, a expressão veiculada pela frase seria a mesma se pronunciada diversamente, por exemplo noutra Língua ou simplesmente por outra voz ou por outra grafia, caso seja escrita.

Já por outro lado, esta mesma expressão não poderia deixar de ter por base o facto real de uma vivência judicativa - ou seja, não haveria juízo objectivo sem julgar subjectivo, ou ainda, não haveria idealidade da significação sem realidade da vivência de dar significação.

Mas, em contrapartida, há que notar que a significação não se confunde com esta vivência de dar significação; nem sequer depende dela para lá do

thesis that every user of the name must be in possession of the description; just as Kripke is not committed to holding that every user of the expression 'one meter' knows about the meter rod in Paris by saying that its reference is fixed by the descripton 'Lenght of stick $\mathrm{S}$ in Paris'." (Evans, 1973: 295-296)

"We have so far considered 'the well-understood expression' as a concrete experience. Instead of considering its two types of factor, the expression's appearance and the sense-conferring or sense-fulfilling experience, we wish to consider what is, in a certain fashion, given "in" these: the expression itself, its sense and its objective correlate. We turn therefore from the real relation of acts to the ideal relation of their objects or contents. A subjective treatment yields too one that is objective." (Husserl, 1901, I: 194-195 (§11)). Sublinhados nossos. 
estrito facto de ter de ser suscitada por um acto real. Assim, enquanto as vivências de dar significação se situam na ordem das relações reais entre actos, as significações objectivas são necessariamente da ordem das relações ideais entre objectos (e conteúdos). E de facto, diz-nos Husserl, o julgar acontece e deixa de acontecer, ao passo que o julgado permanece o mesmo na sua significação objectiva - "o meu acto de julgar é uma vivência efémera, que nasce e morre. Não o é, porém, o que diz o enunciado. [...] Os actos de julgar serão diferentes em cada caso. Mas o que julgam, o que o enunciado diz, é sempre o mesmo."6

Ainda de um ponto de vista meramente descritivo, Husserl desenreda três entendimentos, a não confundir, do que seja a expressão de um enunciado judicativo, a saber, a expressão como manifestação, como significação e, finalmente, como objecto ou referente.

“Os termos 'manifestação', 'significação' e 'objecto' pertencem essencialmente a toda a expressão. Em toda a expressão há algo manifestado, algo significado e algo nomeado ou de outro modo designado. Em cada um destes casos, falar de 'expressão' é equívoco."”

Seja um enunciado judicativo da forma 'S é P'. Podemos, pois, dizer que este enunciado exprime - no sentido de manifestar - uma vivência real, a saber, o acto de julgar; exprime também - no sentido de significar - o juízo na sua idealidade; exprime finalmente - no sentido de referir - a objectividade acerca da qual o juízo afirma algo.

Estes três planos, de acordo com a Primeira Investigação, estão implicados em qualquer expressão, como um conjunto de condições necessárias. Ou, dito de outro modo, toda a expressão manifesta (ou notifica), significa e refere. Com efeito, uma expressão que não possuísse significação não seria efectivamente uma expressão - por exemplo, 'verde é ou', ${ }^{8}$ pelo que não é o caso que haja expressões desprovidas de significação. Além disso, afirma Husserl, "usar com sentido uma expressão é o mesmo que se referir expressivamente ao objecto (representar o objecto)", 9 pelo que não é o caso que haja significação de uma expressão sem um objecto referido. Por fim, como já podemos explicitar, também não é o caso que se possa pensar uma expressão sem a realidade, por ela notificada, do acto expressivo.

6 "My acte of judging is a transient experience: it arises and passes away. But what my assertion asserts [...] neither arises nor passes away. It is an identity in the strict sense." (Husserl, 1901, I: $195(\$ 11))$

7 "Relational talk of 'intimation', 'meaning' and 'object' belongs essentially to every expression. Every expression intimates something, means something and names or otherwise designates something. In each case, talk of 'expression' is equivocal." (Husserl, 1901, I: 199 $(\S 14))$

8 Husserl, 1901, I: $201(\S 15)$

9 "To use an expression significantly, and to refer expressively to an object (to form a presentation of it), are one and the same." (Ibidem) 


\section{III \\ (Demarcação face às teorias descritivista e causal)}

Note-se, desde já, que para Husserl a referência expressiva a um objecto não está dependente da existência do objecto referido - "não importa que o objecto exista ou seja fictício ou mesmo impossível"10 -, ou seja, de uma forma mais genérica, podemos dizer, a partir das teses expostas na Primeira Investigação Lógica, que a teoria husserliana da referência não está ontologicamente comprometida. A Quinta Investigação confirma a mesma ideia ao deixar claro que quando nos referimos a algo não o fazemos diferentemente pelo facto de isso a que nos referimos não existir realmente, seja por engano seja por resultar da imaginação. ${ }^{11}$ Por exemplo, não nos referimos ao deus Júpiter e à torre de Babel de uma maneira diferente daquela com que nos referimos a Bismark ou à catedral de Colónia. ${ }^{12}$

A respeito deste compromisso ontológico, e face à bem conhecida posição de tradição fregeana (hoje bastante generalizada) de que uma expressão só refere se o seu referente existir, ${ }^{13}$ já Husserl respondia, ainda que de forma incompleta e no contexto de uma avaliação das teses de John Stuart Mill, nos seguintes termos:

Na sua relação com o seu objecto, o nome próprio não é nenhum sinal. Isso se vê, sem a menor dúvida, ao pensar que ao sinal é essencial o assinalar um facto, uma existência, ao passo que o objecto nomeado não necessita de valer como existente. ${ }^{14}$

Este descomprometimento ontológico da referência, mesmo da referência dos nomes próprios, fazendo-se no presente caso o contraste com os sinais (não há sinal sem que exista o assinalado, mas pode haver nome sem que exista a coisa nomeada), é um dos pontos fundamentais, embora não o único, de uma clivagem face às teorias semânticas de herança fregeana, mesmo as conhecidas como anti-descritivistas.

10 "It makes no difference whether the object exists or is fictitious or even impossible." (Ibidem)

11 "If I represent God to myself, or an angel, or an intelligible thing-in-itself, or a physical thing or a round square etc., I mean the transcendent object named in each case, in other words my intentional object: it makes no difference whether this object exists or is imaginary or absurd." (Husserl, 1901, V: 127 (\$11))

12 "It makes no essential difference to an object presented and given to consciousness whether it exists, or is fictitious, or is perhaps completely absurd. I think of Jupiter as I think of Bismark, of the tower of Babel as I think of Cologne Cathedral, of a regular thousand-sided polygon as of a regular thousand-faced solid." (Husserl, 1901, V: 99 (§11))

13 "Whatever is referred to must exist." (Searle, 1969: 77)

14 "But in its relation to its object the proper name is not an index. This is at once clear when we reflect on the fact that it is of the essence of an index to point to a fact, an existence, whereas the object named need not be taken to exist at all." (Husserl, 1901, I: $204(\S 16)$ ) 
Outro aspecto desta clivagem reporta-se à relação semântica entre significação e referência e, mais particularmente, ao que se entende de facto por significação e referência.

Husserl afirma que toda a significação implica uma referência, bem como a conversa. Como já mencionámos, afirma ainda que usar com sentido uma expressão é o mesmo que referir um objecto. No entanto, isto não nos autoriza a concluir (de forma confusa, aponta mesmo Husserl) que a significação de uma expressão é o objecto por ela referido.

"Ouve-se muitas vezes falar de significações como se por significação se entendesse os objectos significados, uso que dificilmente terá sido mantido com consequência, pois nasce de uma confusão com o autêntico conceito de significação". ${ }^{15}$

As razões para desfazer a confusão são claras. As afirmações de que não há significação sem referência nem referência sem significação não devem obscurecer os factos de que diferentes significações podem obter a mesma referência objectiva e, conversamente, que diferentes referências objectivas podem obter a mesma significação. Exemplificando:

1. As expressões 'O vencido de Waterloo' e 'O vencedor de Iena' têm o mesmo referente, Napoleão Bonaparte, embora expressem significações muito distintas.

2. Um termo geral - por exemplo, o termo "homem" - tem uma significação precisa, embora possa referir diferentes homens particulares. ${ }^{16}$

No que respeita a 1 . há um manifesto acordo com a teoria semântica de Frege - diferentes sentidos podem determinar referências idênticas, tornando, aliás, provida de valor cognitivo a afirmação de identidades não triviais entre expressões com a mesma referência, por exemplo a afirmação de que o vencido de Waterloo é o vencedor de Iena.

Já no que respeita a 2., poder-se-á questionar se a referência de um termo geral consiste em cada um dos objectos ou indivíduos que perfazem a extensão, muito de acordo com o entendimento de Mill quanto à denotação, ou se,

15 "Meanings are often spoken of as signifying the objects meant, a usage that can scarcely be maintained consistently, as it springs from a confusion with the genuine concept of meaning." (Husserl, 1901, I: 202 (§15))

16 "Two names can differ in meaning but can name the same object, e.g. 'the victor at Jena' 'the vanquished at Waterloo'; 'the equilateral triangle' - 'the equiangular triangle'. [...] It can happen, conversely, that two expressions have the same meaning but a different objective reference. The expression 'a horse' has the same meaning in whatever context it occurs. But in one occasion we say 'Bucephalus is a horse', and on another 'That cart-hoorse is a horse', there has been a plain change in our sense-giving presentation in passing from the one statement to the other." (Husserl, 1901, I: 197-198 (§12)) 
diversamente, consiste na classe tomada em geral. ${ }^{17}$ Mas porventura mais importante, dentro da teoria semântica de Husserl, será a seguinte observação - se à mesma significação podem corresponder diferentes referências objectivas, então seguir-se-ia, aparentemente, que deveria existir um outro modo (não mediado pela significação) de uma consciência referir intencionalmente um objecto. Mas tal afirmação não encontra sustento; aliás, Husserl é, a este respeito, peremptório: "Uma expressão adquire referência objectiva apenas porque significa e que, portanto, se diz com razão que a expressão designa (nomeia) o objecto mediante a sua significação". ${ }^{18}$

Esta afirmação poderia, por seu turno, induzir-nos a fazer uma leitura descritivista da semântica de Husserl, designadamente no que respeita à determinação da referência objectiva das expressões. Mas é aqui que se encontra o passo mais importante da semântica da primeira das Investigações Lógicas, no que respeita a um contraste a fazer face quer às semânticas ditas descritivistas, quer às semânticas ditas anti-descritivistas.

Em primeiro lugar, Husserl distingue muito claramente o comportamento semântico dos nomes próprios do comportamento de outras expressões que designam à custa de atributos, afirmando daqueles que se tratam de expressões dotadas de significação, mas que referem de modo não atributivo. Ora, com isto ficam desde logo estabelecidas duas diferenças da maior importância:

- por um lado, a diferença entre significação e significação atributiva (esta última está para a primeira como uma espécie para o género);

- e por outro, fica perfeitamente assinala a discriminação entre referência directa (que Kripke virá ulteriormente a caracterizar como rígida) e referência via atributos (que Kripke virá ulteriormente a caracterizar como flexível) ${ }^{19}$.

Estas diferenças, indisputavelmente assinaladas por Husserl, anulam de pronto qualquer tentativa de fazer uma leitura descritivista da semântica da Primeira Investigação. Embora toda a referência se faça via uma significação, tal não quer dizer que se faça via uma significação atributiva.

Mas já por outro lado, é igualmente curto-circuitada qualquer tentativa de proceder a uma leitura que dispense a significação, pois é ainda mediante esta,

17 Nota-se, a respeito de 2., de forma muito particular a influência do System of Logic de John Stuart Mill, designadamente o seu primeiro livro, intitulado "Of Names and Propositions", no qual a denotação é entendida de tal forma que o denotatum não é a classe, mas cada um dos objectos da classe. Na sua obra de exposição do pensamento de J. S. Mill, John Skorupski tece o seguinte comentário - "The relation of denotation holds between the name, and each and every such thing. Mill's 'denote' is equivalent to 'is true of', or 'is truly predicable/ affirmable of'." (Skorupski, 1989: 51)

18 "An expression only refers to an objective correlate because it means something, it can be rightly said to signify or name the object through its meaning." (Husserl, 1901, I: $198(\S 13)$ )

19 Neste ponto, é pois clara a precedência de Husserl sobre a distinção, supostamente criada por Russell, entre duas funções semânticas irredutíveis, a de referir, directa e imediata, e a de denotar, indirecta e mediada. Enquanto Husserl, como vimos, estabelece a distinção em 1901, Russell só o fará no seu “On Denoting” de 1905. 
pese embora já não atributiva, que uma expressão pode, para Husserl, obter referência objectiva.

\section{IV \\ (O descritivismo e a teoria causal aquém do problema da referência)}

Uma coisa é saber de que maneiras se pode fixar a referência de uma expressão; outra, distinta, é saber como pode uma expressão referir algo; outra ainda é saber como se constitui um objecto de referência, i.e, o referente propriamente dito, independentemente do facto de ser referente de uma expressão. Há que notar que, a respeito das duas últimas questão, nem a teoria descritivista nem a teoria causal da referência alcançam uma resposta satisfatória. Senão vejamos:

(1) Uma descrição definida em uso atributivo, ${ }^{20}$ embora possa fixar, atributivamente, o referente de um termo genuinamente referencial, por exemplo um nome próprio, não o constitui. Como se sabe isto? Porque, por um lado, pressupõe as referências, e respectivas fixações, dos termos que a compõem; e porque, por outro lado, mais não faz do que circunscrever um domínio de tal maneira que um e apenas um objecto - obviamente já constituído - o satisfaça.

(2) Por sua vez, os termos genuinamente referenciais que compõem uma descrição definida em uso atributivo, bem como nomes próprios e descrições definidas em uso referencial, mesmo no mais estrito respeito pela teoria causal, não constituem o seu referente. Como se sabe isto? Simplesmente, por tais termos só referirem em virtude de uma fixação da referência e por tal fixação consistir na estipulação de um objecto, já individuado como objecto de experiência.

(3) Considerando (1) e (2), podemos dizer que todos os designadores, sejam de que natureza forem, e estejamos a pensar no descritivismo ou na teoria causal, pressupõem a constituição do referente. Quer isto dizer que ambas as teorias procuram responder ao problema da fixação da referência, mas em nada contribuem para uma resposta ao problema da constituição dos referentes.

20 A distinção entre dois usos, um atributivo (correspondente à teorização de Russell das descrições definidas) e outro referencial, das descrições definidas deve-se a Keith Donnellan - "I will call the two uses of definite descriptions I have in mind the attributive use and the referential use. A speaker who uses a definite description attributively in an assertion states something about whoever or whatever is the so-and-so. A speaker who uses a definite description referentially in an assertion, on the other hand, uses the description to enable his audience to pick out whom or what he is talking about and states something about that person or thing." (Donnellan, 1966: 237) 
Por outro lado, o facto de uma descrição definida em uso atributivo ter fixado a referência de um termo genuinamente referencial não faz com que esse termo deixe de referir o seu referente, mesmo que este, numa situação contrafactual, já não satisfaça a descrição definida. Como se sabe isto? Por exemplo, 'Camões' não deixaria de designar Camões se, contrafactualmente, se tivesse que Camões não fosse o autor de Os Lusíadas, ainda que eu tivesse fixado a referência da expressão 'Camões' através da descrição definida 'O autor de Os Lusíadas'. Por isso, a teoria causal alega que o descritivismo não explica como sucede as expressões referenciais referirem o que referem.

O descritivismo prestou atenção a um modo de fixar a referência, um modo importante, pois não evitamos, na maior parte das circunstâncias, fazer acompanhar todas as expressões por uma descrição definida como que para atestar que sabemos do que falamos, ou seja, que conhecemos das coisas nomeadas mais do que o nome. Contudo, e esse é o ponto da teoria causal, os nomes próprios não referem em virtude das descrições definidas. Na verdade, e como vimos em (1), mesmo as descrições definidas pressupõem a referência, nos termos referenciais que a compõem.

Por seu turno, a teoria causal prestou atenção a outro modo de fixar a referência, um modo também importante, assente no contacto com o referente e na transmissão em cadeia dessa fixação. Contudo, também não é em virtude dessa relação causal que as expressões referem o que referem, pois para que haja uma relação causal com o referente é preciso que este exista realmente (ou tenha existido), quando, na verdade, não é o caso, como bem notou Husserl, que um referente tenha de existir para que se lhe possa fazer referência. Por exemplo, admitindo que a questão sobre a existência ou inexistência de Deus é indecidível, então a questão sobre se a palavra 'Deus' tem ou não tem referência seria, admitindo a teoria causal da referência, ela própria indecidível. Ora, sejamos crentes ou ateus, quando empregamos a palavra 'Deus' referimo-nos certamente a algo e de forma competente. Com efeito, seria tão absurdo alegar que por me referir a Deus temos implicada a existência de Deus como por crer que Deus não existe temos implicada a inexistência de referência para a expressão 'Deus'. ${ }^{21}$

21 Ray Jackendoff lista um conjunto de seis categorias de objectos problemáticos para uma teoria da referência realista:

"(1) Fictional and mythical characters

a. Sherlock Holmes

b. The unicorn in my dream last night

(2) Geographical objects

a. Wyoming

b. The Mississippi River

c. The distance between New York and Boston

(3) Virtual objects

(4) Social entities 
Assim, também sobre o problema de saber o que faz as expressões referenciais referirem, ambas as teorias, a causal e a descritivista, não são satsfatórias. E por estas razões, se não argumentamos mal, parecem-nos pertinentes as duas teses semânticas sustentadas por Husserl na sua $1 .{ }^{a}$ Invest. Lógica - que nem toda a significação é atributiva, mas que toda a referência é, de algum modo, mediada por uma significação.

Daqui não se segue, porém, que neste texto Husserl tenha dado resposta aos problemas de saber o que faz uma expressão referir e como se constitui o referente. Em Ideias I também não se encontram facilmente elementos capazes de fornecer essas respostas, pelo menos de forma compatível com a $1 .{ }^{a}$ Investigação. Na verdade, existem diversas interpretações, sobretudo provenientes da tradição analítica, que, no que respeita a Ideias $I$, sustentam uma leitura fregeana do pensamento de Edmund Husserl. De acordo com tal leitura, a referência (Bedeutung) seria determinada por um Sinn atributivo ou, nos termos, da obra de 1913, o Sinn noemático, de natureza atributiva, seria aquilo por que se relacionaria a consciência com o seu objecto. Por outras palavras, Ideias I aproximam Husserl do descritivismo. Porém, este texto está longe de poder ser encarado como a última palavra de Husserl sobre o assunto.

\section{V \\ (Respostas em Experiência e Juizo)}

Se nenhuma expressão refere sem que tenha sido fixada a sua referência, e se tal fixação consiste na estipulação de um objecto, já individuado, como referente de uma expressão, então, tal individuação, não podendo sustentar-se nem numa relação causal nem numa significação atributiva, pressupõe uma
a. The value of my watch
b. The first dollar I ever earned
c. Morris Halle's Ph.D. degree
d. Your reputation
e. General Motors
f. The score of tomorrow's Red Sox game
(5) Auditorily perceived objects
a. Mahler's Second Symphony
b. The words banana and despite

(6) Other

a. The set of all possible worlds

b. The best of all possible worlds" (Jackendoff, 2002: 301-303)

O seu comentário geral é este - "The quotes above assert that we refer to "objects in the world' as if this is completely self-evident. It is self-evident, if we think only of reference to middle-sized perceivable physical objects like tables and refrigerators. But as soon as we explore the full range of entities to which we actually refer, 'the world' suddenly begins to be populated with all sort of curious beasts whose ontological status is far less clear." (Jackendoff, 2002: 303) 
constituição subjectiva e ante-predicativa. Genericamente, podemos dizer que todas as expressões (ou designadores), seja qual for a sua natureza, pressupõem a prévia constituição ante-predicativa dos seus referentes. Por outras palavras, tratar-se-á de tematizar a experiência ante-predicativa enquanto experiência objectiva, isto é, em que é dada a unidade do objecto através da multiplicidade das suas apresentações. Uma tal tematização é levada a cabo de forma explícita e sistemática na obra póstuma de Husserl Experiência e Juizo (Erfahrung und Urteil), designadamente na sua primeira secção, intitulada 'A experiência ante-predicativa (receptiva)'.

Uma segunda questão ressalta ainda da necessidade de articulação entre os dois planos que, entretanto, foram suscitados - um ante-predicativo, a que se reporta o acto referencial a uma objectidade, outro predicativo, a que se reportam os actos referenciais fundados, entre eles, a referência via um sentido atributivo. Perguntas como 'de que modo se faz a passagem do plano ante-predicativo ao predicativo?', 'como se converte a objectidade ante-predicativamente constituída num sujeito de predicados a ela ulteriormente atribuídos?' - perguntas que não encontram resposta nem nas Investigações Lógicas nem em Ideias I -, encontram na segunda secção de Experiência e Juizo ("O pensamento predicativo e as objectividades do entendimento") um esforço explícito no sentido da obtenção de uma resposta fenomenológica.

Importa notar que estas questões, além de pertinentes no debate contemporâneo sobre o problema da referência, também assumem importância decisiva numa avaliação mais geral da fenomenologia de Husserl. Isto, pelo menos por duas razões. Primeiramente, porque tem sido alvo de severas críticas a tese husserliana de uma constituição ante-predicativa de objectos. Aqui o criticismo tem seguido pelo menos uma via - a de uma rejeição da própria ideia de que possa haver objectos que não sejam constituídos predicativamente, o que conduz à proposta de pensar o plano ante-predicativo como um plano ainda pré-objectivo, de "entes". ${ }^{22}$ A segunda razão prende-se com a ideia, a nosso ver atribuível quer ao Husserl das Investigações Lógicas quer ao de Ideias I, da inexistência de um "lugar" para os qualia na experiência consciente. ${ }^{23}$

\section{VI (Experiência ante-predicativa)}

Os juízos na sua forma mais simples são juizos de experiência que atribuem algo - um predicado - a um substrato derradeiro, o qual começa, previamente, por ser objecto de experiência. Não há, dito de outro modo, juízo de experiência sem a prévia experiência (portanto, pré-judicativa e ante-predica-

${ }^{22}$ Esta é uma linha de argumentação que vem desde Ser e Tempo de Heidegger. Cf. Paisana, 1992. 
tiva) do objecto individual sobre o qual virá a recair o juízo e a predicação inerente a este. Significa isto que uma teoria fenomenológica do juízo, da actividade predicativa em geral, de uma referência intencional atributiva e provida de valor epistémico, não poderá ser levada a cabo sem uma prévia elucidação fenomenológica da experiência qualificada como ante-predicativa. ${ }^{24}$ Consequentemente, a respeito desta, Husserl compromete-a prontamente com o que já é da ordem do individual:

A experiência, no seu sentido primeiro e autêntico, define-se como uma relação directa ao individual. ${ }^{25}$

Ora, logo aqui encontramos a ideia de uma relação directa, referência originária ao objecto, explicitamente dado na sua individualidade, mas num plano ante-predicativo. Contrariamente ao modo como o descritivismo pensa a referência, esta é, originariamente (ou seja, logo na experiência ante-predicativa), uma referência directa, ainda que só possível sob a mediação de uma significação (desta feita, contrariando a teoria causal). Mas mais importante é notar, aqui, que o problema da referência passa a poder ser tratado, na sua especificidade, independentemente de estar em causa uma expressão referir. Por outras palavras, sendo a experiência, ante-predicativamente constituída, desde logo, relação directa ao individual - ou seja, desde logo referência -, então atender à constituição do referente é, ao mesmo tempo, atender à instauração da relação referencial propriamente dita, não entre uma expressão e um referente, mas, mais originariamente, entre uma consciência e um referente. ${ }^{26}$

Em que termos pensa, então, o fenomenólogo a constituição ante-predicativa do objecto, enquanto primeiro substrato de um juízo de experiência? Em primeiro lugar, antes da apreensão propriamente dita do objecto na sua individualidade, dá-se uma sua afecção, significando aqui afectar o processo pelo qual o objecto se destaca de um ambiente em seu redor no qual se encontra pré-dado. ${ }^{27}$ Mas, além disso, antes de qualquer interesse teórico, mesmo antes de qualquer interesse prático que venha suscitar a individuação, por assim dizer, do objecto, esta pré-doação, segundo Husserl, consiste numa "crença passiva". Nestes termos, pode ler-se que "o objecto afecta a partir do seu campo, é um objecto, um ente entre outros, já pré-dado numa crença pas-

24 "La théorie de l'expérience anté-prédicative, de l'expérience qui donne dans l'évidence objective les substrats les plus originaires, est l'élément premier en soi de la théorie phénoménologique du jugement." (Husserl, 1938: 21 (§6))

25 "L'experience au sens premier et authentique se définit ainsi comme une relation directe à l'individuel:" (Husserl, 1938: $21(\S 6)$ )

26 Quer isto dizer que uma teoria da referência pode, deve mesmo, ser pensada independentemente de uma teoria das expressões referenciais. Conversamente, uma teoria da referência das expressões referenciais, sejam estes designadores rígidos ou flexíveis, nomes próprios ou descrições definidas, pode ser pensada supondo a referência.

27 "Préalablement à la saisie, il y a toujours l'affection, qui n'est pas l'affecter d'un objet isolé singulier. Affecter veut dire: se détacher d'un entour qui est toujours co-présent [...]" (Husserl, 1938: $24(\S 7))$ 
siva". ${ }^{28}$ A tal "solo originário", campo a partir do qual o objecto afecta, e no qual o objecto encontra-se já dado, embora não na sua individualidade, mas numa crença passiva, Husserl faz corresponder, mais precisamente, uma crença no mundo, "crença passiva universal no ser". ${ }^{29}$ Donde, Husserl afirmar que "a consciência do mundo é uma consciência que tem por modo a certeza da crença". 30

Assim, se a experiência ante-predicativa é a experiência de objectos individuais apreendidos, então, sob estes, e como condição de uma sua apreensão, há que reportar uma afecção que parte de um mundo, ainda não segmentado em objectos, mas crido enquanto ser existente. Note-se, porém, que esta anterioridade do mundo enquanto totalidade não é cognoscível após a efectiva doação do objecto na sua individualidade. Por isso, apesar da precedência da totalidade do mundo face à individualidade do objecto - é daquela que esta se destaca -, o interesse cognitivo só poderá tematizar o mundo enquanto totalidade através da constituição individual de objectos. ${ }^{31}$

Agora, este objecto que afecta não é pré-dado de uma tal forma que se pudesse dizer dele ser inteiramente indeterminado, como um mero X prévio a toda a actividade determinativa. De acordo com Husserl, o mundo é sempre para nós um mundo tal que o conhecimento já aí realizou o seu trabalho de múltiplas maneiras; e, assim, é indubitável que não há nenhuma experiência no sentido primeiro e autêntico de uma experiência da coisa, que, captando essa coisa, pela primeira vez, e tomando-a no conhecimento, não "saiba" já mais alguma coisa sobre ela do que aquilo que vem assim ao conhecimento. ${ }^{32}$

Ora, este saber já actuante por antecipação, pré-saber que limita a indeterminação do objecto (tornando, pois, possível a pré-doação própria à experiência ante-predicativa) reenvia, como sua condição, à distinção entre efectividade e possibilidade. E esta possibilidade, muito de acordo com os princípios do associativismo humeano, reenvia, por seu turno, para "sínteses de associação" já estabelecidas quer por similitudes quer por oposições, que articulam o campo perceptivo que serve de pano de fundo da experiência. Quer isto dizer que a contrapartida da indeterminação do objecto destacável é uma

28 "L'objet affecte à partir de son champ, il est un objet, un étant parmi d'autres, il est déjà prédonné dans une croyance passive." (Husserl, 1938: 24 (§7))

29 Cf. Husserl, 1938: 25 (§7).

30 "La conscience du monde est une conscience qui a pour mode la certitude de la croyance..." (Husserl, 1938: $25(\S 7)$ )

31 "Le monde comme tout est toujours déjà donné dans la certitude passive, et l'orientation de la connaissance vers un étant singulier est génétiquement plus originaire que celle vers le monde comme tout [...]" (Husserl, 1938: $26(\S 7)$ )

32 "Le monde est pour nous toujours tel qu'en lui la connaissance a toujous déjà accompli son œuvre, sous les formes plus variées ; et ainsi il est hors de doute qu'il n'y a pas d'expérience, au sens simples et premier d'expérience de chose qui, s'emparant de cette chose pour le première fois, la portant à la connaissance, ne 'sache' pas déjà d'elle davantage que ce qui vient ainsi à la connaissance." (Husserl, 1938: $26(\S 8)$ ) 
complexa estruturação, mas em si mesma imperceptível, do campo de fundo, segundo a homogeneidade e a heterogeneidade, a presença e a ausência. ${ }^{33}$ Assim, se há uma possibilidade que informa a efectividade no campo perceptivo, é porque esta efectividade, antes, ainda enquanto apenas campo sensível, informou aquela possibilidade. É nestes termos que a experiência perceptiva, ainda ante-predicativa, envolve uma antecipação ou, mais exactamente, uma indução de um horizonte de possibilidades que pré-constitui o experienciado.

Se há experienciado individual, pois, é porque há um horizonte de possibilidades, um horizonte interno a cada objecto experienciado. Mas também, em segundo grau, um horizonte externo de "objectos co-dados", ${ }^{34}$ distinguindo-se desta forma o que é um do que é plural. Perguntar-se-ia, porém, sobre como diferenciar o co-dado enquanto pluralidade e não apenas unidade. A isto, Husserl responde que os objectos co-dados reportam-se a um único e mesmo "horizonte espácio-temporal" - daí, a sua co-doação plural -, mas cada qual segundo esta ou aquela "típica" 35 ou "tipo a priori", definindo este como "generalidade indeterminada, mas que permanece identificável como a mesma". ${ }^{36}$ Em consequência, cada novo objecto, se constituído originalmente face aos objectos já alguma vez, no passado, constituídos, corresponderá necessariamente uma nova típica, um novo tipo a priori.

Esta tipificação, pela qual se constitui a apreensão dos objectos singulares, não se resume, porém, a tipos particulares - como se a cada objecto correspondesse o seu tipo e nada mais. Além disso, estão envolvidos tipos mais gerais, tipos para colecções de objectos semelhantes ou dissemelhantes quanto a este ou aquele aspecto, tipos para colecções de coleç̧ões, etc. Assim, cada objecto não é destacado do mundo apenas pelo seu tipo particular; destacando-se, outros tipos mais gerais destacam notas desse objecto enquanto relevando-o de objectidades mais gerais. ${ }^{37}$ De certo modo, por aqui verifica-se que com o objecto a destacar-se do fundo, também este, por notas gerais e acompanhando aquele, se vai destacando numa apreensão integrada.

Em contrapartida, observe-se que os tipos a priori, mais ao menos particulares, mais ou menos gerais, não constituem por inteiro, digamos assim, os

33

34

35

36

"La chose, une réalité (Real) quelconque comme objet d'expérience possible, a son a priori général, qui en est la pré-connaissance: c'est une généralité indeterminée, mais qui reste identifiable comme la même; c'est la généralité d'un type a priori appartenant à un espace de jeu de possibilités a priori." (Husserl, 1938: 32 (\$8))

37 "Le monde qui nous est pré-donnée l'est-il toujours comme multiforme, informé selon une multitude de genres, d'espèces particuliers, etc. Cela veut dire que ce qui nous affecte en arrière-plan, et qui est ressaisi pour la première fois en une prise active, est connu en un sens beaucoup plus étendu encore: cela est déjà saisi passivement en arrière-plan non seulement comme 'objet', objet d'expérience, ex-plicable, mais comme chose, comme homme, œuvre humaine, et ainsi dans des particularités plus poussées encore." (Husserl, 1938: $35(\S 8)$ ) 
objectos. Constituem-nos o suficiente para que sejam identificáveis como os mesmos, mas, de resto, numa indeterminação geral no que respeita à sua estrutura interna tal qual é pré-dada num "primeiro olhar". Pese embora, esta pode ser, segundo Husserl, mais ou menos dilucidada através de um processo a que chama 'explicação', ${ }^{38}$

Neste quadro, temos dado o modo como a apreensão passiva do objecto individual se realiza segundo o Husserl de Experiência e Juizo. Obtido, assim, o objecto individual na experiência ante-predicativa, designadamente na experiência perceptiva, tem-se, pois, constituído o substrato primeiro dos juízos mais simples, os de experiência. Note-se que Husserl fala de constituição passiva, mesmo apenas pré-constituição do objecto e não de uma sua objectivação, pois reserva esta para o trabalho do Eu enquanto espontaneidade e fonte de crença activa já no plano de uma espontaneidade predicativa. ${ }^{39}$

\section{VII \\ (A espontaneidade predicativa)}

À “apreensão receptiva”, Husserl contrapõe uma "espontaneidade predicativa", com aqual o mesmo objecto, $S$, apreendido passa a ser um sujeito de atributos que lhe são predicados através de uma actividade judicativa ou atributiva. É, pois, o mesmo pólo objectivo, pré-constituído na apreensão receptiva, e dotado de um "sentido objectivo", mas do ponto de vista lógico ainda inteiramente indeterminado, que agora se dá como substrato de um processo de predicação, através do qual é constituído o seu "sentido lógico".

Naturalmente, o "sentido lógico" de um objecto não esgota a totalidade da sua significação; esta está em parte, mais precisamente no que respeita à síntese passiva da apreensão, já constituída aquando a passagem ao plano lógico ou predicativo. Trata-se do que Husserl denomina 'sentido objectivo'. ${ }^{40}$ Mas, já por outro lado, é apenas através daquela significação lógica que um

38 “...L'expérience renvoie à la possibilité - et il s'agit d'un pouvoir du Je -, non seulement d'ex-pliquer progressivement la chose que a été donnée à un premier regard, à partir de cette donnée dans son ipséité, mais aussi d'obtenir peu à peu, au fur et à mesure de son déroulement, de nouvelles déterminations de cette même chose. Toute expérience peut être étendue en une chaîne continue d'expériences singulières ex-plicatrices, unies synthétiquement en une expérience unique, ouverte à l'infini, du même." (Husserl, 1938: 27 (§8))

39 "Toute conscience passive est déjà 'constituante d'objets', - plus exactement pré-constituante. Mais c'est seulement l'activité d'objectivation, de connaissance, l'activité du Je, de degré inférieur ou supérieur, qu n'est pas seulement doxa passive, qui crée les objets de la connaissance et du jugement." (Husserl, 1938: 64 (§13))

$40 \mathrm{O}$ contraste entre sentido objectivo e sentido lógico, aquele constituído na passividade apreensora, ainda ante-predicativa, este constituído através de operações predicativas de uma actividade atributiva é-nos claramente exposto ao longo de todo o $\S 56$ de Experiência e Juizo. 
objecto se converte em objecto de conhecimento, sem, como já se afirmou, deixar, por isso, de ser o mesmo objecto.

Como pólo idêntico de acções predicativas, como portador do sentido lógico, o objecto tornou-se, em sentido próprio, objecto de conhecimento. Isto não quer, naturalmente, dizer que o objecto como pólo de actividades receptivas e o objecto como pólo de espontaneidades predicativas seriam dois objectos diferentes. ${ }^{41}$

Entre os dois planos, o ante-predicativo e o predicativo, para empregar a linguagem de Experiência e Juizo, existe um ponto de ligação que é, desde logo, assinalado - o objecto da intentio, que consiste no mesmo em ambos os planos, pré-constituído na passividade ante-predicativa, logicamente constituído como sujeito de predicados na espontaneidade atributiva. Por outro lado, se o objecto da predicação pressupõe como sua condição a sua pré-doação ante-predicativa, então resulta clara a articulação entre sentido lógico e sentido objectivo: a constituição do sentido lógico depende da prévia constituição do sentido objectivo, ainda que este não valha senão como uma condição necessária, mas não suficiente.

[...] Todo o enriquecimento do sentido lógico pressupõe um enriquecimento na receptividade. Uma síntese espontânea de identificação não pode ter lugar senão aí onde já sucedeu uma apreensão receptiva e uma ex-plicação. Mas, por outro lado, esta mudança do sentido lógico tem, no entanto, uma independência específica face àquilo que tem lugar na receptividade. Pode-se constituir um sistema de contemplação receptiva, edificado de maneira complexa, no que respeita ao interior e ao exterior do objecto; um objecto pode bem, sob o fundamento destas operações de contemplação, ter sido visto de todos os seus lados na maior plenitude possível da intuição, sem que com isso uma só etapa da apreensão predicativa tenha dela resultado necessariamente. ${ }^{42}$

Por esta razão, diversamente do objecto de uma primeira predicação que não é senão o mesmo da apreensão receptiva, entre o sentido lógico e o sentido

41 "Comme pôle identique des actions prédicatives, comme porteur du sens logique, l'objet est devenu au sens propre objet de connaissance. Cela ne veut naturellement pas dire que l'objet comme pôle d'activités réceptives, et le objet comme pôle des spontanéités prédicatives seraient deux objets différents [...]" (Husserl, 1938: 279 (§56)).

42 “...Tout enrichissement du sens logique présuppose un enrichissement dans la réceptivité. Une synthèse spontanée d'identification ne peut avoir lieu que là où l'ont déjà précédée une saisie réceptive et une ex-plication. Mais, d'un autre côté, ce changement du sens logique a pourtant une indépendance spécifique à l'égard de ce qui a lieu dans la réceptivité. Il peut s'être constitué un système de contemplation réceptive, édifié de façon complexe, concernant l'intérieur et l'extérieur de l'objet ; un objet peut bien, sur le fondement de ces opérations de contemplation, avoir été vu de tous côtés dans la plus grande plénitude possible d'intuition, sans que pour autant une seule étape de saisie prédicative en soit nécessairement résultée." (Husserl, 1938: 277 (§56) 
objectivo não se pode falar de uma tal maneira que se dissesse que são o mesmo. Dito de outro modo, se há uma homologia entre o objecto da espontaneidade e o objecto da receptividade, não é, porém, o caso que essa homologia se estenda aos sentidos correlativos, o lógico e o objectivo. Com efeito, já vimos atrás que a significação lógica não esgota toda a significação do objecto, falta-lhe "o carácter 'deíctico' do visar, do prestar atenção a". ${ }^{43}$ Mas, em contrapartida, falta ao sentido objectivo a fixação cognitiva das determinações do objecto - o juízo é o lugar em que se fixam, quais sedes de depósito do conhecimento, tais determinações. ${ }^{44}$

Nisto, reconhece-se, mudando o que há a mudar, a ideia de que o conhecimento apenas se expressa de forma descritivista e que, por isso, as identidades entre termos co-referenciais - seja Véspero=Fósforo - só são epistémica ou cognitivamente relevantes porque subentendem descrições definidas.

\section{VIII (a compacidade)}

Defendemos atrás que a rejeição do descritivismo pode ser lida como a tese da transcendência de todo e qualquer objecto relativamente à sua determinabilidade; e que a rejeição da teoria causal, por seu turno, pode ser lida como a exigência de que, não obstante, há que dar conta de uma constituição do objecto enquanto objecto.

Como tese adicional, sustentaremos agora, e ainda com base em Experiência e Juizo, que um objecto não pode coincidir com a sua determinabilidade porque nele se verifica uma compacidade que aquela não tem meio de constituir e que essa compacidade do objecto é dada na crença do mundo.

Nesse sentido, comecemos por fazer uma analogia com o conceito de 'mundo' de Experiência e Juizo. Este significa aqui um fundo universal de que os objectos individuais se destacam através de tipos a priori indutores. $\mathrm{O}$ ponto para que chamamos a atenção é que, evidentemente, a colecção completa de todos os objectos destacados do mundo não vale como o mundo propriamente dito. Aquela colecção, por mais completa que seja, não é capaz, por princípio, de constituir o fundo. Agora, e exactamente da mesma forma, a colecção completa das determinações que destacam cada um dos objectos individuais não é capaz, por princípio, de constituir o objecto na sua compacidade.

O nosso ponto, em rigor, não se fica por aqui. Não se trata de apontar apenas uma analogia entre o mundo qua fundo e uma pretensa, mas carente de justificação se apenas posta assim, compacidade dos objectos destacados do mundo. Fundamentalmente, o nosso ponto consiste em afirmar que os objectos 
destacados do mundo são, na verdade, parcelas de fundo que se destacam do fundo originário que é o mundo. A compacidade dos objectos ao destacar-se da compacidade do próprio mundo é como que herdada.

Aliás, não fora esta compacidade, carácter de fundo dos objectos, e não se afirmaria, a respeito de todo e qualquer objecto, a sua inesgotável possibilidade de determinação, a sua infinita determinabilidade.

Posto que é esta compacidade, ou carácter-de-fundo, o que faz com que todo e qualquer objecto transcenda a sua determinabilidade, então também não é o caso que o objecto possa ser constituído pela sua determinabilidade. Todos os objectos são objectos-de-fundo, pelo que o que deles se destaca não os possa constituir.

Ora, se há uma presunção constitutiva dos objectos individuais através de determinações, através da sua síntese, seja sob o fluxo de fases temporais, seja sob um associativismo indutor, no Husserl de Da Sintese Passiva e de Experiência e.Juizo, tal porém não pode ser entendido sem o subentendimento de que o carácter-de-fundo está dado pelo mundo. Nesta última obra, afirma-se que, mesmo sob uma relativa indeterminação, há já suficiente determinação na experiência perceptiva para que um objecto seja pré-dado na experiência perceptiva. Afirma-se, além disso, que quando um objecto é constituído pela primeira vez o que sucede é a constituição de um novo tipo particular, a partir do qual aquele possa ser induzido.

\section{IX \\ (O carácter-individuado dos objectos)}

Acabamos de constatar que Husserl é capaz de responder ao problema da transcendência dos objectos relativamente às suas determinabilidades próprias enquanto nesse problema apenas estiver envolvida a compacidade - o carácter de objectos-de-fundo - de todos os objectos. Com efeito, ao afirmar que os objectos se constituem destacando-se de um mundo-fundo, Husserl salvaguarda essa compacidade dos objectos destacados. Aliás, se o mundo é o correlato originário de uma crença passiva na sua posição de ser, temos então explicada a razão por que há também, a respeito dos objectos destacados, pertinência em falar de uma referência directa, e de crença nas suas posições qua seres. O mundo pode ele mesmo ser considerado, na sua totalidade não diferenciada, a intentio originária de que todos os actos referenciais, todas as posições de Ser se desdobram.

Contudo, o assinalado carácter-de-fundo dos objectos não explica como possam estes ser constituídos de forma individuada. A este aspecto chamaremos carácter-individuado dos objectos.

Atendendo à experiência ante-predicativa de objectos individuais e à referência directa, sem designador, a um $X$, que defendemos ser, originaria- 
mente, o próprio mundo-fundo, se uma colecção de determinações, sobre os princípios de semelhança e de diferença, e o contraste entre homogeneidade e heterogeneidade, induz uma estrutura de invariância, tal estrutura só vale como objecto, i.e., só satisfaz o seu carácter-individuado, se for assumida, ou melhor, apostada como correlato directo de um acto de referência. Não é, consequentemente, a estrutura de invariância, determinável no "fluxo das fases temporais", para nos exprimirmos nos termos de Husserl, que realmente individua o objecto ${ }^{45}$; o que o põe como indivíduo é o próprio acto de referência intencional. Sem este acto, que não pode, pois, ser rebatido numa pura passividade, tal estrutura induzida passivamente não se constituiria como estrutura de um objecto, antes permaneceria como mero articulado de notas associadas umas às outras, entre si indiscerníveis quanto ao seu estatuto, dotadas de sentido é certo, mas sem se reportarem a um "isto" de que se possa dizer serem a sua estrutura.

O carácter-individuado está, pois, pressuposto no simples acto de referir, sendo da iniciativa deste. Referir não é ir ao encontro de algo individual; antes é, e desde logo, individuar, ainda que de forma tentativa, abdutiva e, por isso, falível.

\section{Bibliografia}

Alves, Pedro, (2002) "Noema e Percepção na Fenomenologia de E. Husserl”. Análise 23 (2002). Porto: Campo das Letras.

BARATA, André, (2001) "Caracteres da Experiência". Phainomenon 2 (2001): pp. 5-36. Lisboa: Colibri.

DONNELlan, Keith, (1966) "Reference and Definite Descriptions" in MARTINICH, 1985: 235-247.

Evans, Gareth. (1973) “The Causal Theory of Names" in MARTINICH, 1985: 295-307. FISETTE, Denis, (1994) Lecture frégéenne de la phénoménologie. Paris: Éditions de l'Éclat.

FREGE, Gottlob, (1892) "Ueber Sinn und Bedeutung". "On Sense and Nominatum". Tr. Herbert Feigl in MARTINICH, 1985.

GrAÇA, Adriana Silva, (2002) "Referência e denotação: duas funções semânticas irredutíveis", in Disputatio 12, Maio 2002, pp.3-21.

HUSSERL, Edmund, (1901) Logische Untersuchungen (2.a ed.). Logical Investigations. Tr. N. Findlay. London: Routledge.

(1905) Zur Phänomenologie des inneren Zeitbewusstseins. Lições para uma fenomenologia da consciência interna do tempo. Tr. Pedro M. S. Alves. Lisboa: IN-CM, 1994.

45 “A posição temporal-fenomenológica amarra, porém, apenas a vivência intencional e não o objecto intencional - ele não é individuado por meio do tempo.” (Citação extraída de Alves, 2002: 35 - Beilage XV, Hua XI, p. 394) 
(1913) Ideen I-Idées directrices pour une phénoménologie. Tr. : Paul Ricoeur. Paris: Gallimard, 1950.

(1918-26) Analysen zur passiven Synthesis. Aus Vorlesungs-und Forschungsmanuskripten (Husserliana, Band XI). De la synthèse passive. Logique transcendantale et constitutions originaires. Tr. Bruce Bégout et Jean Kessler. Grenoble: Jérôme Millon, 1998.

(1938) Erfahrung und Urteil. Expérience et Jugement. Tr. : Denise Souche-Dagues. Paris : P.U.F., 1991.

JACKENDOFF, Ray, (2002) Foundations of Language - Brain, Meaning Grammar, Evolution. Oxford: Oxford University Press.

KRIPKE, Saul, (1971) "Identity and Necessity", in MUNITZ, Milton K. (ed.), Identity and Individuation. New York: New York University Press, pp.135-164. Reprinted in MOORE, A. W., 1993., (1980) Naming and Necessity. Cambridge MA: Harvard University Press.

LYCAN, William G., (2000) Philosophy of Language - A contemporary introduction. London/New York: Routledge.

MARTINICH, Aloysius P. (Ed.), (1985) The Philosophy of Language. Oxford: Oxford University Press, 1996 ( $3 .^{a}$ ed.)

PAISANA, João, (1992) Fenomenologia e Hermenêutica - A relação entre as filosofias de Husserl e Heidegger. Lisboa: Editorial Presença.

PUTNAM, Hilary, (1973) "Meaning and Reference" in MARTINICH, 1985: 308-315.

(1975) Mind, Language and Reality, "The Meaning of 'meaning"'. Cambridge: Cambridge University Press, pp. 215-271.

RusSELL, Bertand, (1905) “On Denoting” in MARTINICH, 1985.

(1919) "Descriptions" in MARTINICH, 1985.

SEARLE, John R., (1969), Speech Acts: An Essay in the Philosophy of Language. New York: Cambridge University Press. [Os Actos de Fala, Coimbra: Livraria Almedina, 1984.]

SKORUPSKI, John

(1989) John Stuart Mill - The Arguments of the Philosophers. London: Routledge, 2000.

\section{ABSTRACT}

No último quartel do Séc. XX, instalou-se na Filosofia da Linguagem um vivo debate entre duas teorias acerca da referência, a teoria descritivista, formulada por Bertrand Russell e com raízes na filosofia de Frege, e, a desafiar esta, a teoria causal da referência, sob o impulso de Putnam e de Kripke. Há, por outro lado, importantes estudos do pensamento de Husserl, centrados sobretudo em Ideias I, que dão conta da possibilidade de uma sua leitura fregeana.

$\mathrm{O}$ intuito desta comunicação reside, primeiramente, em mostrar que, não obstante essas leituras, os aspectos semânticos mais originais na fenomenologia de Husserl e, além disso, também mais interessantes para o debate sobre o problema da referência, se encontram logo na Primeira das Investigações Lógicas. Com efeito, 
nesse texto, cremos ser possível mostrar que a teoria da expressão de Husserl não se ajusta nem à teoria descritivista nem à teoria causal da referência.

As razões do desajustamento, segundo tese que propomos, prendem-se com o facto de ambas as teorias da referência, descritivista e causal, disputarem entre si o problema da fixação da referência das expressões como se esse fosse o problema de saber o que faz com que as expressões refiram.

Mostrar que não é assim com Husserl, conduz-nos a um terceiro problema, na obra póstuma Experiência e Juizo, sobre a constituição dos referentes, enquanto objectos de uma relação directa ao individual, ou seja, enquanto objectos de experiência. Quererá isto dizer, concluindo, que o problema da referência, antes de respeitar às expressões referenciais, respeita à própria experiência e que tal problema deverá, por isso, resolver-se na constituição passiva e ante-predicativa da experiência. 